\title{
Evaluation of progression to diabetes in high-risk patients eligible to attend the 'Walking Away from Diabetes' educational intervention: a retrospective cohort study
}

\author{
LEON JONKER, ${ }^{1}$ STACEY JAYNE FISHER, ${ }^{2}$ ROBERT WESTGATE, ${ }^{3}$ LOUISE OVEREND ${ }^{4}$
}

\begin{abstract}
Aims: To retrospectively assess the efficacy of a pragmatic education programme called 'Walking Away from Diabetes' (WAD), a single-session intervention aimed at patients who are at risk of developing type 2 diabetes mellitus (T2DM). Methods: Baseline and follow-up data for 6,116 patients, identified as 'at risk of diabetes' in the period April 2012 to March 2016, were assessed for T2DM status in January 2018. Any differences in outcome between WAD attenders and nonattenders was explored using Kaplan-Meier, log rank testing and Cox regression analyses.

Results: During the follow-up period, 426 of 3,470 (12.3\%) WAD attenders and 349 of $2,646(13.2 \%)$ non-attenders were diagnosed with T2DM ( $p=0.068$, log rank test). Cox regression showed that $\mathrm{HbA}_{1 \mathrm{c}}$ (hazard ratio (HR) 1.23, $\mathrm{p}<0.001$ ) and high density lipid levels (HR $0.67, p<0.001$ ) rather than WAD attendance (HR $0.89, p=0.11$ ) were the two main factors associated with progress from 'at risk' to T2DM.

Conclusions: Although the wider health impact of the WAD programme was not considered here, session attendance does not appear to reduce the risk of developing T2DM. However, other factors influence the risk of developing T2DM. It is essential for educational programmes, designed to have a preventative effect for people at risk of diabetes, to be assessed for short- and long-term efficacy.

Br J Diabetes 2020;20:15-18
\end{abstract}

Key words: diabetes, education, exercise, lifestyle, patient education, diabetes risk

Science \& Innovation Manager, Cumbria Partnership NHS Foundation Trust, Research \& Development Department, Carlisle, UK

2 Research GP, Cumbria Partnership NHS Foundation Trust, Research \& Development Department, Carlisle, UK

${ }^{3}$ Medical Director, Carlisle Healthcare, St Paul's Medical Centre, Carlisle, UK

${ }^{4}$ Consultant Diabetologist, Cumbria Partnership NHS Foundation Trust,

Diabetes Department, Carlisle, UK

Address for correspondence: $\operatorname{Dr}$ Leon Jonker

Science \& Innovation Manager, Cumbria Partnership NHS Foundation

Trust, Research \& Development Department, Carlisle CA1 3SX, UK

Telephone: 01768245975 E-mail: leon.jonker@cumbria.nhs.uk

https://doi.org/10.15277/bjd.2020.238
Introduction

Lifestyle interventions can enable a reduction in the risk of developing type 2 diabetes mellitus (T2DM) ${ }^{1,2}$ This has been shown in various randomised controlled trials in a variety of populations. ${ }^{1,3-5}$ The aim of the cited studies was to promote more intense physical activity in conjunction with an improvement in healthy diet adherence and weight management for overweight and obese patients. 'Walking Away from Diabetes' (WAD) is a theory-driven structured education programme for people identified at increased risk of T2DM. WAD has been developed within the NHS and is based on a previously published study. ${ }^{6-8}$

To date, there are only clinical outcome data available on the WAD programme from a controlled clinical trial and one-year follow-up. ${ }^{6}$ In that study, WAD did have a statistically significant positive effect on biomedical and lifestyle outcomes. Therefore, investigating the effectiveness of WAD is indicated to appraise whether WAD intervention impacts progression to diabetes in at-risk people.

\section{Methods}

Study design

This concerns a retrospective cohort study and is classed as a service evaluation in accordance with UK Health Research Authority guidelines. Therefore, individual informed consent was not obtained from patients to use their data. Caldicott approval was obtained from the NHS Trust that holds the data to analyse and publish it.

WAD programme details

The WAD programme is described in more detail elsewhere. ${ }^{6,8}$ In summary, it provides three hours of structured education for up to 10 people (and a partner/friend) led by two trained educators. The programme is aimed at promoting walking and, to further enhance the physical activity through walking message, patients are issued with a pedometer to self-monitor the steps they take daily. Other information provided to attendees involves the causes, complications and timelines for glucose intolerance and diabetes. Patients at risk of developing diabetes were identified by being eligible through the Leicester Diabetes Risk Assessment and/or having pre-diabetic haemoglobin $A_{1 c}$ (Hba1c) levels $(42-47 \mathrm{mmol} / \mathrm{mol}){ }^{7}$ This study cohort includes patients 
referred to WAD by GPs in Cumbria between 1 April 2012 and 31 March 2016, and the end date for follow-up was 1 January 2018. Follow-up was retrospective and data were extracted from a national database maintained by the University of Exeter.

\section{Data sources and analysis}

Baseline demographic and clinical measures were taken in the GP surgery when a patient was classified as being at risk of diabetes. These included a patient's residence postcode, sex, age, $\mathrm{HbA}_{1 \mathrm{c}}$, high density lipids (HDL), cholesterol and blood pressure. Patient ethnicity was not recorded, but the study sample is from a county in England where $96.5 \%$ of the population is white British. ${ }^{9}$ Index of multiple deprivation deciles were calculated from patients' postcodes, ${ }^{10}$ with 1 being the highest degree of deprivation, and data on T2DM diagnosis were extracted from the University of Exeter database. Diagnosis of T2DM was based on a $\mathrm{HbA}_{1 \mathrm{c}}$ level $>48 \mathrm{mmol} / \mathrm{mol}$. For continuous and ordinal data, the mean and median, respectively, plus the $95 \%$ confidence interval $(95 \% \mathrm{Cl})$ was calculated. Differences between WAD attender and non-attender cohorts were assessed with the $\mathrm{X}^{2}$ test (binary and nominal data) and Mann-Whitney $\mathrm{U}$ test (ordinal and continuous data). The rate of diagnosis of T2DM over time was considered with a Kaplan-Meier plot accompanied by a log rank test for WAD as a factor on its own, and Cox regression analysis for all variables. Data were collated using Microsoft Excel and analysed using SPSS v20. A p value of 0.05 was considered significant.

\section{Results}

Across the period that the WAD programme ran in this particular NHS Trust, a total of 7,916 patients were identified as being eligible for attendance in primary care and referred to the WAD team in the diabetes department. Of those, 4,420 patients attended and 3,496 did not (56\% attendance rate). Complete datasets, baseline demographic, clinical measurements data and diabetes outcome data were available for 6,116 people who were identified as being at risk of developing T2DM. Therefore, all further data analysis was conducted using the dataset for these patients. The mean follow-up time was 52.0 months (95\% Cl 51.4 to 52.5$)$ for attenders and 48.3 months $(95 \% \mathrm{Cl} 47.7$ to 49.0 ) for non-attenders ( $\mathrm{p}<0.001$, Mann-Whitney $\mathrm{U}$ test). In total, 426 of $3,470(12.3 \%)$ attenders and 349 of $2,646(13.2 \%)$ non-attenders were eventually diagnosed with T2DM during the follow-up period. The baseline variable measurements were not identical between the WAD attendance and non-attendance cohorts. Table 1 shows that they differed in average age, degree of deprivation, HDL level and cholesterol levels. Those who attended WAD were significantly older, less deprived and had a better cardiovascular health profile.

When diabetes diagnosis in relation to solely WAD attendance is considered, log rank analysis and Kaplan-Meier plotting (Figure 1) of diabetes diagnosis cases shows that there is no significant difference in the number of diabetes cases diagnosed during the follow-up period ( $p=0.068$, log rank test). Since this kind of analysis does not take into account any confounding
Table 1 Baseline demographics and clinical measures for patients referred to the 'Walking Away from Diabetes' (WAD) programme

\begin{tabular}{|c|c|c|c|}
\hline Variable & $\begin{array}{l}\text { WAD attenders } \\
(n=3,470)\end{array}$ & $\begin{array}{l}\text { WAD } \\
\text { non-attenders } \\
(n=2,646)\end{array}$ & P value \\
\hline $\begin{array}{l}\text { Age, years, mean } \\
(95 \% \mathrm{Cl})\end{array}$ & $\begin{array}{l}66 \\
(66 \text { to } 67)\end{array}$ & $\begin{array}{l}63 \\
(63 \text { to } 64)\end{array}$ & $<0.001$ * \\
\hline $\begin{array}{l}\text { Sex, n, male/female } \\
(\%)\end{array}$ & $\begin{array}{l}1527 / 1943 \\
(44 \% / 56 \%)\end{array}$ & $\begin{array}{l}1228 / 1418 \\
(46 \% / 54 \%)\end{array}$ & $0.061 \dagger$ \\
\hline $\begin{array}{l}\text { Index of Multiple } \\
\text { Deprivation, decile, } \\
\text { median }(95 \% \mathrm{Cl})\end{array}$ & $\begin{array}{l}6 \\
(5.81 \text { to } 5.98)\end{array}$ & $\begin{array}{l}6 \\
\text { (5.44 to } 5.64)\end{array}$ & $<0.001$ * \\
\hline $\begin{array}{l}\mathrm{HbA}_{1 \mathrm{c}}, \mathrm{mmol} / \mathrm{mol} \text {, } \\
\text { mean }(95 \% \mathrm{Cl})\end{array}$ & $\begin{array}{l}44.2 \\
(44.1 \text { to } 44.3)\end{array}$ & $\begin{array}{l}44.2 \\
(44.1 \text { to } 44.2)\end{array}$ & $0.16^{*}$ \\
\hline $\begin{array}{l}\text { Blood pressure systolic, } \\
\mathrm{mmHg} \text {, mean }(95 \% \mathrm{Cl})\end{array}$ & $\begin{array}{l}133.9 \\
(133.4 \text { to } 134.4)\end{array}$ & $\begin{array}{l}133.9 \\
(133.3 \text { to } 134.5)\end{array}$ & 0.81 * \\
\hline $\begin{array}{l}\text { Blood pressure diastolic, } \\
\mathrm{mmHg} \text {, mean }(95 \% \mathrm{Cl})\end{array}$ & $\begin{array}{l}78.1 \\
\text { (77.7 to } 78.4)\end{array}$ & $\begin{array}{l}78.4 \\
(78.0 \text { to } 78.8)\end{array}$ & $0.30 *$ \\
\hline $\begin{array}{l}\mathrm{HDL}, \mathrm{mmol} / \mathrm{L} \text {, mean } \\
(95 \% \mathrm{Cl})\end{array}$ & $\begin{array}{l}1.48 \\
(1.46 \text { to } 1.50)\end{array}$ & $\begin{array}{l}1.43 \\
(1.41 \text { to } 1.45)\end{array}$ & $<0.001$ * \\
\hline $\begin{array}{l}\text { Total cholesterol, } \\
\mathrm{mmol} / \mathrm{L} \text {, mean }(95 \% \mathrm{Cl})\end{array}$ & $\begin{array}{l}4.91 \\
(4.86 \text { to } 4.95)\end{array}$ & $\begin{array}{l}4.99 \\
(4.84 \text { to } 5.04)\end{array}$ & $0.007 *$ \\
\hline $\begin{array}{l}\text { *Mann-Whitney } U \text { test. } \\
\text { †Chi-squared test. } \\
\mathrm{HbA}_{1} \text {, haemoglobin } \mathrm{A}_{1} \mathrm{c}\end{array}$ & & & \\
\hline
\end{tabular}

Figure 1. Kaplan-Meier plot to assess if attendance at 'Walking Away from Diabetes' (WAD) programme impacts on the rate of subsequent diabetes diagnosis when other variables are not taken into account ( $p=0.068$, log rank test).

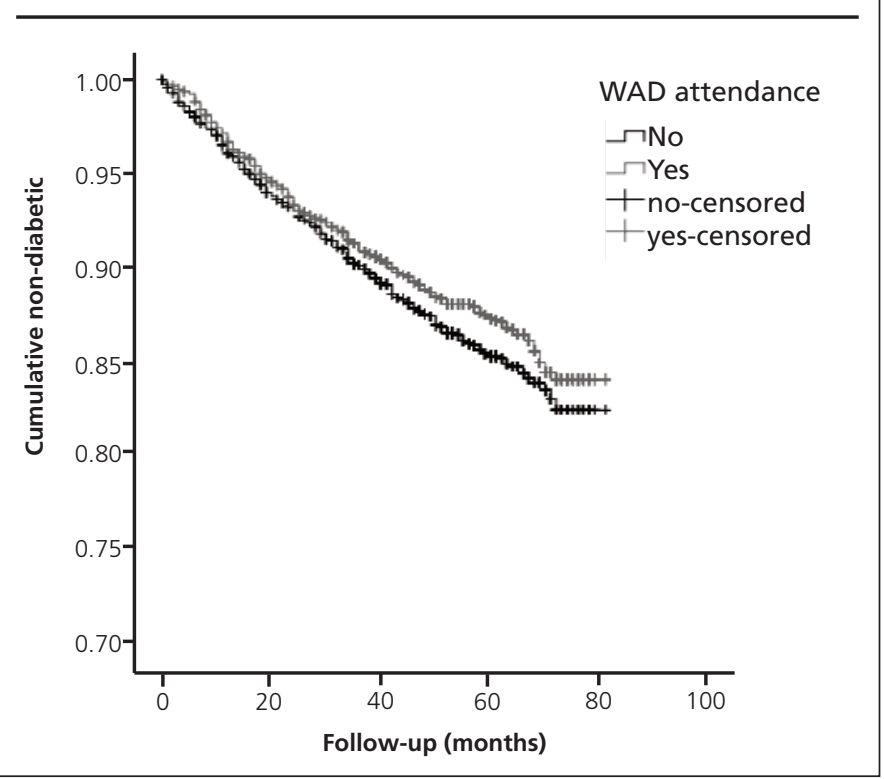


Table 2 Cox regression analysis for diabetes as outcome and follow-up in months as time factor

\begin{tabular}{|c|c|c|c|}
\hline Variable & Hazard ratiot & $95 \% \mathrm{Cl}$ & $P$ value \\
\hline $\begin{array}{l}\text { Deprivation index } \\
\text { rating ( } 1=\text { most deprived, } \\
\text { to } 10=\text { least deprived) }\end{array}$ & 0.97 & 0.94 to 0.99 & $0.018^{*}$ \\
\hline $\begin{array}{l}\text { Patient sex ( } 0=\text { male; } \\
1=\text { female) }\end{array}$ & 1.16 & 0.99 to 1.35 & 0.056 \\
\hline Patient age (years) & 0.99 & 0.98 to 1.00 & $0.019 *$ \\
\hline $\begin{array}{l}\text { WAD attendance } \\
\text { ( } 0=\text { non-attendance; } \\
1=\text { attendance) }\end{array}$ & 0.89 & 0.77 to 1.03 & 0.11 \\
\hline $\begin{array}{l}\text { Blood pressure systolic } \\
(\mathrm{mmHg})\end{array}$ & 1.00 & 0.99 to 1.01 & 0.78 \\
\hline $\begin{array}{l}\text { Blood pressure diastolic } \\
(\mathrm{mmHg})\end{array}$ & 1.01 & 0.99 to 1.01 & 0.31 \\
\hline $\mathrm{HbA}_{1 \mathrm{c}}(\mathrm{mmol} / \mathrm{mol})$ & 1.23 & 1.21 to 1.24 & $<0.001$ * \\
\hline HDL (mmol/L) & 0.67 & 0.56 to 0.81 & $<0.001$ * \\
\hline Cholesterol (mmol/L) & 0.91 & 0.86 to 0.96 & $0.001 *$ \\
\hline \multicolumn{4}{|c|}{ 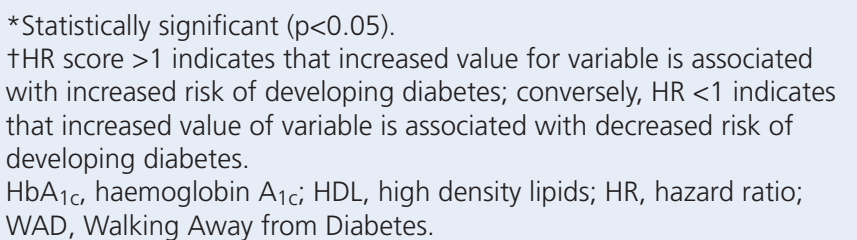 } \\
\hline
\end{tabular}

factors that may influence whether someone develops diabetes, Cox regression analysis was conducted to determine if any variables are associated with diabetes, and if this influences any impact that WAD attendance may have on diabetes developing during the follow-up period. Table 2 shows that $\mathrm{HbA}_{1 \mathrm{c}}$ and $\mathrm{HDL}$ levels are associated most significantly with diabetes risk, both in terms of magnitude (hazard ratio (HR)) and statistical significance ( $p$ value). A higher $\mathrm{HbA}_{1 c}$ level is associated with an increased risk of T2DM whereas a higher HDL level is associated with a lower risk of developing diabetes. Variables significantly associated with T2DM risk but with a negligible HR are deprivation score, patient age and cholesterol. On the other hand, WAD attendance is not significantly linked to the risk of developing diabetes, although there appears to be a trend to a lower risk of diabetes if a patient attends a session ( $p=0.11$, not significant).

\section{Discussion}

This retrospective evaluative study set out to appraise if real-life application of the WAD programme is significantly associated with a reduction in T2DM diagnosis in subsequent years. The study results suggest that WAD programme attendance is not associated with a lower risk of developing T2DM. However, there are a few caveats to bear in mind regarding the data. Although the sample size is large and average follow-up period is considerable, this study is hamstrung by being a retrospective evaluation of the effectiveness of the WAD programme. Consequently, fasting glucose, low-density lipid profiles and some anthropometric measures such as body mass index are not included in the analysis, nor are any data on pre- and post-attendance exercise levels achieved by people in the cohort. The pragmatic 'real-world' approach also means that the diagnosis of diabetes was made on the basis of a single $\mathrm{HbA}_{1 \mathrm{c}}$ measurement in most cases, and the assessment of a population in a single region means the study cohort is almost exclusively white British. A prospective epidemiological study involving both a confirmatory second $\mathrm{HbA}_{1 \mathrm{c}}$ or glucose tolerance test and a more diverse population would be advantageous.

From the available data it is observed that the non-significant reduction seen in T2DM in the WAD attenders can probably be attributed to a multitude of factors. There is a difference in baseline composition of the WAD attenders and non-attenders, both in terms of clinical and non-clinical parameters. Because the patients were able to choose whether to attend or not, rather than being allocated to a specific treatment arm, this could not be controlled for. Both high $\mathrm{HbA}_{1 \mathrm{c}}$ and low HDL levels are recognised risk factors for T2DM as identified in controlled trials and through meta-analysis. ${ }^{11-13}$ In absolute terms, the average follow-up period for non-attenders is 3.7 months shorter, which equates to a $7 \%$ relative difference in follow-up time 'to the benefit' of the non-attendance arm.

Despite the potential confounding role of $\mathrm{HDL}$ and relative difference in follow-up time between attenders and non-attenders, the long-term impact of attending a WAD session on diabetes risk appears modest and inconclusive. This contrasts with a Finnish diabetes prevention programme where short-, medium- and long-term outcomes have been positive. ${ }^{1,14}$ The main difference between the Finnish and WAD programme is the number of times the patient attended an education session: seven sessions with a nutritionist in the first year alone versus one single session with a session practitioner, respectively. The achieved attendance rates are similar for both programmes, with a $>50 \%$ participation rate recorded. In the present study we did not explore the medium- to long-term wider positive impact that the WAD programme may have from a patient perspective, and therefore one has to be mindful that it may have other unintended positive effects bar prevention of T2DM.

National policy means that the WAD programme has been superseded by the 'Healthier You: NHS Diabetes Prevention Programme' that has been rolled out across England using various programme delivery providers. ${ }^{15,16}$ The limited effectiveness observed in this present evaluation of the WAD programme may be due to a number of reasons, but the intensity of the intervention may be the key reason. Similar to the Finnish programme on which it is based, ${ }^{17}$ the 'Healthier You' programme involves numerous (at least 13) education and exercise sessions of 1-2 hours each. The potential role of confounding factors - demographic, anthropometric and clinical - should be taken into 


\section{Key messages}

- Evaluative data on the long-term diabetes prevention effect of a single educational session for at risk people are lacking

- The protective effect of attending the NHS-developed 'Walking Away from Diabetes' (WAD) programme appears to be limited, although effectiveness analysis should take into account the role of confounding factors

- More intense educational programmes have been introduced in the NHS recently; however, as for WAD, their effectiveness should be measured with other variables (including, for example, high density lipid levels) taken into account

account when evaluating the new 'Healthier You' programme. Early indications are that similar trends are observed as in the WAD cohort, with older female patients more likely to attend. ${ }^{18}$

\section{Conclusions}

The single-session WAD education programme may not significantly slow down the rate of T2DM manifesting in people at risk of diabetes. More recent published data suggest that extended and more intense education programmes may be more effective in preventing progression to diabetes. However, evaluations of programmes need to be mindful of confounding variables such as patients' lipid profiles and potential non-intended health benefits that a programme may bring.

\section{Conflict of interest None.}

Funding This research did not receive any specific grant from funding agencies in the public, commercial, or not-for-profit sectors.

\section{References}

1. Tuomilehto J, Lindstrom J, Eriksson JG, et al. Prevention of type 2 diabetes mellitus by changes in lifestyle among subjects with impaired glucose tolerance. N Engl J Med 2001;344:1343-50.

https://doi.org/10.1056/NEJM200105033441801

2. Yamaoka K, Tango T. Efficacy of lifestyle education to prevent type 2 diabetes: a meta-analysis of randomized controlled trials. Diabetes Care 2005;
28:2780-6. https://doi.org/10.2337/diacare.28.11.2780

3. Knowler WC, Barrett-Connor E, Fowler SE, et al. Reduction in the incidence of type 2 diabetes with lifestyle intervention or metformin. $N$ Engl I Med 2002;346:393-403. https://doi.org/10.1056/NEJMoa012512

4. Kosaka K, Noda M, Kuzuya T. Prevention of type 2 diabetes by lifestyle intervention: a Japanese trial in IGT males. Diabetes Res Clin Pract 2005; 67:152-62.

5. Ramachandran A, Snehalatha C, Mary S, et al. The Indian Diabetes Prevention Programme shows that lifestyle modification and metformin prevent type 2 diabetes in Asian Indian subjects with impaired glucose tolerance (IDPP-1). Diabetologia 2006;49:289-97.

https://doi.org/10.1007/s00125-005-0097-z

6. Yates T, Davies M, Gorely T, Bull F, Khunti K. Effectiveness of a pragmatic education programme aimed at promoting walking activity in individuals with impaired glucose tolerance: a randomized controlled trial. Diabetes Care 2009;32:1404-10. https://doi.org/10.2337/dc09-0130

7. Gray LJ, Taub NA, Khunti K, et al. The Leicester Risk Assessment score for detecting undiagnosed type 2 diabetes and impaired glucose regulation for use in a multiethnic UK setting. Diabet Med 2010;27:887-95. https://doi.org/10.1111/j.1464-5491.2010.03037.x

8. Westgate R, Yates T, Troughton J, Stribling B, Khunti K, Davies MJ. Implementation of a structured education programme aimed at the prevention of type 2 diabetes within routine primary care: p280. Diabetes UK conference, 2011.

9. Cumbria Observatory, population data on ethnicity, 2011. https://www.cumbriaobservatory.org.uk/population/ (accessed 3 July 2019)

10. Index of Multiple Deprivation. https://www.gov.uk/government/statistics/english-indices-of-deprivation-2015 (accessed 3 July 2019)

11. Edelman D, Olsen MK, Dudley TK, Harris AC, Oddone EZ. Utility of hemoglobin A1C in predicting diabetes risk. J Gen Intern Med 2004; 19:1175-80. https://doi.org/10.1111/j.1525-1497.2004.40178.x

12. Schmidt MI, Duncan BB, Bang $\mathrm{H}$ et al. Identifying individuals at high risk for diabetes: The Atherosclerosis Risk in Communities study. Diabetes care 2005;28:2013-18. https://doi.org/10.2337/diacare.28.8.2013

13. Look AHEAD Research Group. Long term effects of a lifestyle intervention on weight and cardiovascular risk factors in individuals with type 2 diabetes: four year results of the Look AHEAD trial. Arch Intern Med 2010; 170:1566-75. https://doi.org/10.1001/archinternmed.2010.334

14. Lindström J, Ilanne-Parikka P, Peltonen $M$, et al. Sustained reduction in the incidence of type 2 diabetes by lifestyle intervention: follow-up of the Finnish Diabetes Prevention Study. Lancet 2006;368(9548):1673-9. https://doi.org/10.1016/S0140-6736(06)69701-8

15. NHS Diabetes Prevention Programme. https://www.england.nhs.uk/diabetes/diabetes-prevention/ (accessed 3 July 2019)

16. Healthier You Diabetes Prevention Programme. https://preventing-diabetes.co.uk/ (accessed 3 July 2019).

17. Penn L, Rodrigues A, Haste A, et al. NHS Diabetes Prevention Programme in England: formative evaluation of the programme in early phase implementation. BMJ Open 2018;8(2):e019467. http://dx.doi.org/10.1136/bmjopen-2017-019467

18. Barron E, Clark R, Hewings R, Smith J, Valabhii J. Progress of the Healthier You: NHS Diabetes Prevention Programme: referrals, uptake and participant characteristics. Diabet Med 2018;35:513-18. https://doi.org/10.1111/dme.13562 